\title{
THE NATURAL HISTORY OF VENTRICULAR SEPTAL DEFECT
}

\author{
BY \\ L. BROTMACHER AND MAURICE CAMPBELL \\ From the Cardiac Department, Guy's Hospital and the Institute of Cardiology
}

Received July 26, 1957

The classical picture of ventricular septal defect-striking physical signs of little importance but for the risk of bacterial endocarditis-was formerly accepted, though it rested mainly on the single case, without necropsy, described by Roger in 1879. Taussig (1947) suggested that the defects were of two types: low defects with the classical picture and high defects where there were likely to be large pulmonary arteries and some symptoms. Selzer (1949), studying 80 reported cases and 12 post-mortem records of the San Francisco Hospital, found no support for this anatomical distinction. He concluded that the effects depend on the size of the defect; and that with a small defect there is little hæmodynamic change, while with a large one there is overloading of the pulmonary artery and finally hypertrophy, strain, and failure of the right ventricle. He thought that cyanosis was absent from uncomplicated cases, and that its presence and the appearances during angiocardiography were sometimes more reliable guides than was the pathological specimen itself in distinguishing between acyanotic cases and those with Eisenmenger's complex.

In 1948, cardiac catheterization in one of our patients demonstrated that a septal defect was ventricular and not, as we thought, atrial. Since then we, like others working at the subject, have found many examples of ventricular septal defect with a large left-to-right shunt. Dexter et al. (1947), Handelsman et al. (1948), and Burchell et al. (1948) reported some cases, and Wood (1950) and Joly et al. (1951) found that large defects were common and small ones uncommon. Marquis (1950) stressed that they were often the cause of death in children. Wood et al. (1954) reviewed the history of the maladie de Roger and emphasized that the effects of the lesion depend on the size of the defect and the consequent size of the shunt.

The association with a high pulmonary arterial pressure has been widely recognized (Wood, 1950; Blount et al., 1955; and Kjellberg et al., 1955), but the natural history of the changes in the lesser circulation has received scant attention, one reason being the impracticability of making serial observations on individual patients. The present study is based largely on 75 patients who had catheterization, but another 100 in whom the diagnosis rests at present only on clinical grounds have been used in the section on age and sex incidence. Emphasis is laid on the course of the disease and on the changes in the size of the shunts and in the pulmonary pressure and resistance with age. Patients with central cyanosis are included and the possibility of the aorta being normally placed in some and over-riding in others has been disregarded.

Principles and Classification. Unless the aorta arises entirely from the right ventricle, the right-to-left shunt depends on functional rather than anatomical causes-on the relative pressures in the two ventricles rather than on whether the aorta is over-riding or normally placed. Even when it is anatomically over-riding it can receive little if any blood from the right ventricle as long as the pressure in the right ventricle is lower than in the left, and under such conditions there is a large left-to-right shunt through the defect. We shall try to show that as the right ventricular pressure (which is often high in small children) rises further and as the pulmonary arteriolar resistance rises, this shunt becomes smaller and may ultimately be mixed with or replaced by a rightto-left shunt with an aorta that is now functionally over-riding. 
Cases of the maladie de Roger (Group 1) and of Eisenmenger's complex (Group 5) are, therefore, the two ends of a continuous series of cases of ventricular septal defect: we think these two eponymous terms, and still more the term Eisenmenger's syndrome used by Wood (1956), have outlived their usefulness and should no longer be used in clinical medicine. Ventricular septal defects may be classified as follows.

(1) Small defects with a small left-to-right shunt only (up to 3 or perhaps 3.5 litres a minute). 9 cases.

(2) Larger defects with a left-to-right shunt of 4-15 litres a minute, still with a normal pulmonary arterial pressure. 6 cases.

(3) Larger defects with pulmonary hypertension that is hyperkinetic, with a left-to-right shunt only. 21 cases.

(4) Larger defects, still with a left-to-right shunt only and with pulmonary hypertension that is due to increased pulmonary arteriolar resistance (above 3 units). 12 cases.

(5) Larger defects with a right-to-left shunt also. Here the aorta is functionally over-riding; it may always have been anatomically over-riding or may have become so. 27 cases.

The figures show how many of our 75 cases belonged to each group: if we included those where the diagnosis rests on clinical grounds alone, Groups 1-4 would be enlarged much more than Group 5, but any further subdivision would be very uncertain (see Table III). Our classification represents to some extent the stage that has been reached rather than a permanent division. Cases in Group 1 and possibly in Group 2 remain there and some in Groups 4 and 5 may always have been there but with the passing of time cases in Groups 3 and 4 tend to pass to Group 5.

Most authors who have written on the subject recently have adopted a classification somewhat similar to this. Selzer (1954) made his main division between those where the pressure in the right ventricle was substantially equal to that in the left and those where it was less: he subdivided the latter into those with a small shunt and no rise of pressure and those with a larger shunt and some rise, and the former into those with a shunt that was still left-to-right only and those with a rightto-left shunt also. Wood (1954 and 1956) added the important distinction of a rise of pressure that was hyperkinetic only, making this his third group, and his fourth those with a " severe V.S.D." with raised pulmonary vascular resistance: he did not include cases with a right-to-left shunt, which would have made a fifth group. With this addition, his classification is substantially the same as ours, except that our second group, like the first, contains only those with a normal pulmonary pressure: if this is raised we think they are better in the third group because the rise is generally considerable. The dividing line between our groups 4 and 5 is such a narrow one, with patients moving across when they change from resting to exercising, that the cyanotic cases must be included in any classification of ventricular septal defect. The five groups of Mannheimer et al. (1957) correspond roughly with our five but we think ours are made more precise by using the pulmonary resistance.

The following patient (Case 44, Table VI) is a good example of the natural history. As a girl, she led a normal life and no comment was made on her heart, even when she joined the W.A.A.F. at the age of 17 years. Her first symptoms started then during her physical training: she became breathless and cyanotic on exercise and fainted several times. She was discharged on these grounds and worked as a typist, but gradually became rather worse.

When 21, she came in for investigation: her cyanosis could hardly be seen when she was resting in bed, but increased greatly with exercise. The finger nails showed striking curvature but only slight clubbing otherwise, the characteristic beak fingers of slight or intermittent cyanosis. Her heart was not generally enlarged (c.t.r. $48 \%$ ) though the right ventricle was; and the pulmonary arteries showed increased pulsation (Fig. 1).

Her arterial oxygen saturation was 92 per cent at rest and 85 during catheterization, but fell to 50 per cent with exercise, confirming that the right-to-left shunt, which was trivial at rest, became large with exercise. There was also a large left-to-right shunt $\left(\mathrm{O}_{2}\right.$ saturation: R.A. 48; low R.V., 56; mid R.V., 62; high R.V. 68; and P.A. 67\%). The catheter passed easily from the right ventricle into the aorta (Fig. 1B): the pressures in both sides of the heart were substantially the same (aorta 103/71; P.A. 101/56, and R.V. $103 / 8 \mathrm{~mm}$. Hg. Five years later, she could still earn her living and walk a mile, but was rather more breathless and cyanotic. 


\section{Cyanotic Patients}

Of our 75 patients, 23 had central cyanosis even at rest and an arterial $\mathrm{O}_{2}$ saturation under 90 per cent. It was between 90 and 96 per cent at rest in another 4 who were borderline and have been included with the cyanotic group, for two were generally cyanotic at rest with hæmoglobin percentages of 107 and 109 and two became cyanotic on exertion. Even among the acyanotic patients there was sometimes a dusky hue that made it hard to exclude a minimal degree of central cyanosis, and the arterial $\mathrm{O}_{2}$ saturation was more often between 90 and 94 per cent than in most clinically acyanotic conditions. Many of these probably had small right-to-left shunts and these are shown in Table VI.

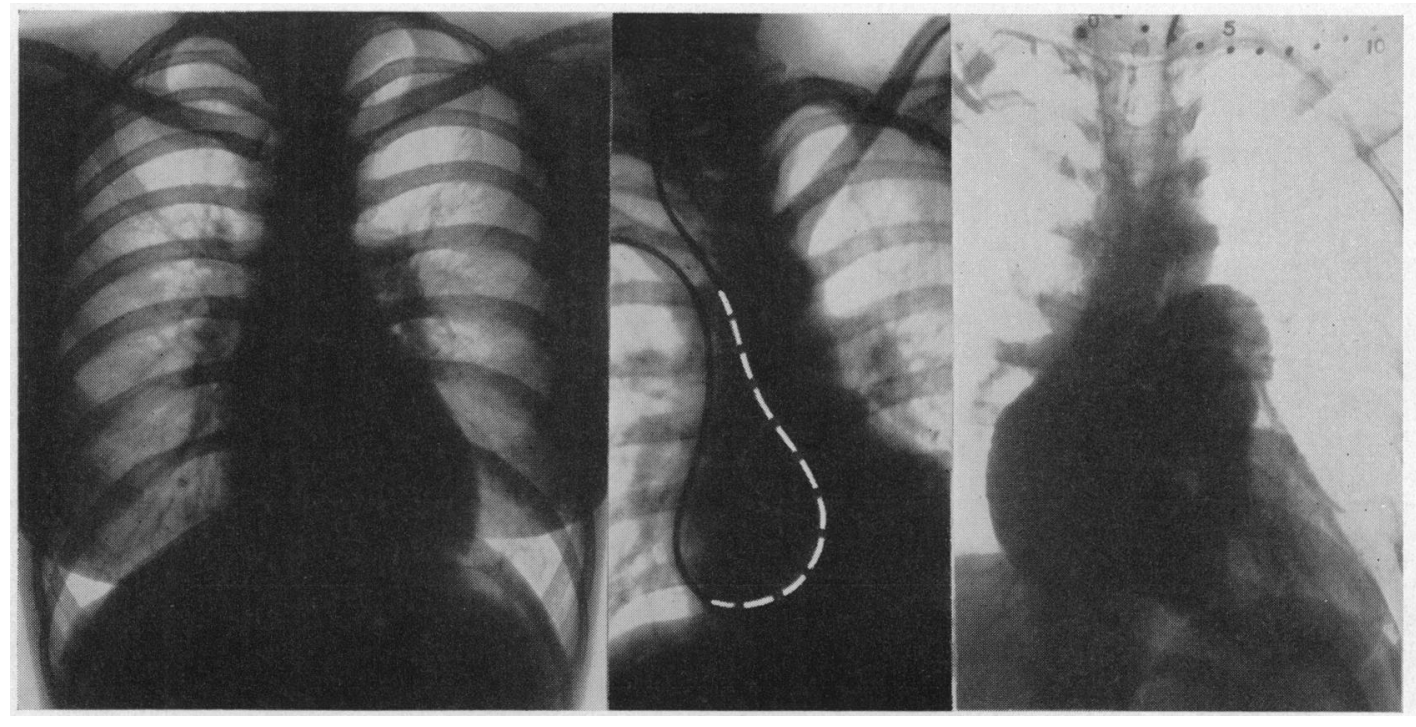

A

B

C

FIG. 1.-(A) Teleradiogram from a woman, aged 21 at the time she was developing a reversed shunt from pulmonary hypertension, showing a normal-sized heart and pleonæmic lung fields. (B) The catheter has passed from the right ventricle to the aorta and from there to the innominate and right carotid arteries. (C) Simultaneous filling of the aorta and its branches and of a rather large pulmonary artery before there has been significant filling of the left ventricle at angiocardiography. All Case 44.

The cyanotic patients included a much larger proportion of adults for more than half were over 20 years of age (see later). It was difficult to be sure when their cyanosis started and this in general will have to be established by direct observation. Five of the 12 children seemed to have been cyanosed from infancy and the other seven from somewhere between the ages of 4 and 10 . In one boy, aged 14, and in one girl, aged 13, who were under regular observation, it was first noted when they were 8 years old.

Nine of the 15 adults gave a story of some tendency to cyanosis from infancy or childhood, but some of these may have had peripheral cyanosis that became central later. Several of these had no doubt that they had become much bluer a few years before they were seen (probably the start of central cyanosis), often at the time when they became more disabled. But an equal number reported cyanosis from childhood without any great change later. The remaining six gave a more precise history of the onset of cyanosis: their average age was 33 (range 21-45) and it had started at an average age of 29 (range 17-40). In two the observations seemed completely reliable: in the girl who has been quoted it started at 17, and in a woman, aged 31, her central cyanosis started at 29 and before this had been peripheral only.

On the whole, the cyanosis was not severe as judged by the standards of Fallot's tetralogy: in five the arterial $\mathrm{O}_{2}$ saturation was between 75 and 79 per cent, in nine between 80 and 84 per cent, 
in nine between 85 and 90 per cent, and in four (all borderline cases) above this. Corresponding to this, the mean hæmoglobin percentage was 115 with a usual range from 100 to 129 per cent. This is rather less than in simple pulmonary stenosis with a right-to-left shunt through an unsealed foramen ovale, where the mean was 120 with a usual range from 100 to 139 ; and much less than in Fallot's tetralogy, where the mean was 134 with a usual range from 120 to 149 per cent (Campbell, 1954).

Transposition. The transition from the acyanotic to the cyanotic form of ventricular septal defect is generally a gradual one. In the same way it may be difficult clinically to distinguish the latter from cases of transposition of the aorta and pulmonary trunk, especially when this is partial. When cyanosis has been present from birth it may be difficult to decide to which group a patient belongs, even after catheterization. Most such patients have probably been excluded from this series by confining it to those where the pulmonary artery was entered from the right ventricle. Difficulty may, however, arise when the aorta alone is completely transposed to the right ventricle.

\section{Age AND Sex INCIDENCE}

Age Incidence. More than three-quarters of our 175 patients were under twenty and more than half under ten years of age. The age incidence in the acyanotic and cyanotic patients was, however, very different: only 10 per cent of the acyanotic were over 20 but nearly half the cyanotic were over this age (Tables I, II, and III).

TABLE I

Age Incidence of Acyanotic Cases of Ventricular Septal Defect

\begin{tabular}{|c|c|c|c|c|c|c|}
\hline \multirow{2}{*}{$\begin{array}{c}\text { Age } \\
\text { (in years) }\end{array}$} & \multicolumn{4}{|c|}{ Number of cases } & \multicolumn{2}{|c|}{ Percentages } \\
\hline & $\begin{array}{l}\text { Present } \\
\text { series * }\end{array}$ & $\begin{array}{l}\text { Wood } \\
\text { (1956) }\end{array}$ & $\begin{array}{l}\text { Selzer } \\
\text { (1949) }\end{array}$ & Total & Acyanotic & All cases \\
\hline $\begin{array}{l}0-10 \\
11-20 \\
21-30 \\
31-40 \\
41 \text { and over }\end{array}$ & $\begin{array}{r}25 \\
19 \\
2 \\
2 \\
0\end{array}$ & $\begin{array}{r}37 \\
22 \\
7 \\
4 \\
2\end{array}$ & $\begin{array}{l}52 \dagger \\
16 \\
7 \\
9 \\
8\end{array}$ & $\begin{array}{r}114 \\
57 \\
16 \\
15 \\
10\end{array}$ & $\begin{array}{l}54 \\
27 \\
7 \cdot 5 \\
7 \\
4 \cdot 5\end{array}$ & $\begin{array}{r}46 \\
23 \\
13 \\
12 \\
6\end{array}$ \\
\hline Total & 48 & 72 & 92 & 212 & 212 & 300 \\
\hline
\end{tabular}

* Our series was classified as 0-9, 10-19, etc., but the others as $0-10,11-20$, etc., but the error introduced by combining them in Tables I and II is not thought to affect our conclusions.

$\dagger$ Twenty-six were under one year of age and this high incidence in infants was also found in the series of Becu et al. (1956).

TABLE II

Age Incidence of Cyanotic Cases of Ventricular Septal Defect

\begin{tabular}{c|c|c|c|c|c|c|c}
\hline $\begin{array}{c}\text { Age } \\
\text { (in years) }\end{array}$ & $\begin{array}{c}\text { Present } \\
\text { series * }\end{array}$ & $\begin{array}{c}\text { Wood } \\
(1957)\end{array}$ & $\begin{array}{c}\text { Selzer and } \\
\text { Laquer } \\
(1951)\end{array}$ & Total & Male & Female & Percentage \\
\hline $0-10$ & 7 & 12 & 6 & 25 & 16 & 9 & 28 \\
$11-20$ & 5 & 5 & 3 & 13 & 8 & 5 & 15 \\
$21-30$ & 5 & 13 & 4 & 22 & 9 & 13 & 25 \\
$31-40$ & 7 & 6 & 7 & 20 & 8 & 9 \\
41 and over & 3 & 2 & 3 & 8 & 2 & 45 & - \\
\hline Total & 27 & 38 & 23 & 88 & 43 & 45 & \\
\hline
\end{tabular}

* See note to Table I. 
TABLE III

Age Incidence of 100 Cases of V.S.D. With Clinical Diagnosis only

\begin{tabular}{|c|c|c|c|c|c|c|c|c|c|c|}
\hline \multirow{3}{*}{ Age (in years) } & \multicolumn{6}{|c|}{ Acyanotic cases: estimated size of shunts } & \multicolumn{2}{|c|}{ Cyanotic cases } & \multicolumn{2}{|c|}{ Total } \\
\hline & \multicolumn{2}{|c|}{ Small } & \multicolumn{2}{|c|}{ Moderate } & \multicolumn{2}{|c|}{ Large } & \multirow[b]{2}{*}{$\mathbf{M}$} & \multirow[b]{2}{*}{$\mathrm{F}$} & \multirow[b]{2}{*}{$\mathbf{M}$} & \multirow[b]{2}{*}{$\mathrm{F}$} \\
\hline & $\mathbf{M}$ & $\mathbf{F}$ & $\mathbf{M}$ & $\mathrm{F}$ & M & $\mathrm{F}$ & & & & \\
\hline $\begin{array}{l}0-9 \\
10-14 \\
15-19 \\
20 \text { and over }\end{array}$ & $\begin{array}{l}7 \\
1 \\
2 \\
2\end{array}$ & $\begin{array}{l}5 \\
3 \\
2 \\
2\end{array}$ & $\begin{array}{r}25 \\
2 \\
2 \\
1\end{array}$ & $\begin{array}{r}13 \\
1 \\
4 \\
3\end{array}$ & $\begin{array}{r}5 \\
2 \\
- \\
-\end{array}$ & $\begin{array}{r}6 \\
1 \\
- \\
-\end{array}$ & $\begin{array}{r}2 \\
3 \\
1\end{array}$ & $\begin{array}{l}1 \\
2 \\
1 \\
1\end{array}$ & $\begin{array}{r}39 \\
8 \\
4 \\
4\end{array}$ & $\begin{array}{r}25 \\
7 \\
7 \\
6\end{array}$ \\
\hline Total & 12 & 12 & 30 & 21 & 7 & 7 & 6 & 5 & 55 & 45 \\
\hline
\end{tabular}

$\mathbf{M}=$ Male patients.

$\mathrm{F}=$ Female patients.

As the number of our proved cases was relatively small we have combined them with the similar series of Wood (1956 and 1957) and with the necropsy series of Selzer (1949) and of Selzer and Laquer (1951) making 212 acyanotic and 88 cyanotic cases. Nearly half of the 300 were under 10 years of age, nearly three-quarters under 20 , and only 6 per cent over 40 (see Table I). Clearly from these figures the outlook for longevity is poor, only 31 per cent having reached 20 and 18 per cent 30 years of age-a prognosis that is much worse than that of atrial septal defect or persistent ductus but better than that of Fallot's tetralogy. There are patients with defects so small that they are hardly significant, but they are not many. It is difficult to understand how the myth that all ventricular septal defects were minor lesions of little or no importance can ever have been accepted.

In these three series, which have the same general trends (see Tables I and II), the age incidence of the acyanotic and cyanotic cases separately is very different. Among the acyanotic there was a rapidly diminishing incidence in the first four decades, the figures being 54, 27, 8, and 8 per cent: among the cyanotic this was much more even, the figures being $28,15,25$, and 23 per cent. This type of age incidence can be found only with a condition that is not lethal-and no one has suggested this of cyanotic ventricular septal defect-or with one that is replenished by fresh cases as some of the earlier ones die. It must, therefore, represent a steady change of cases from acyanotic to cyanotic and, as our experience suggests, this often happens in the first three decades. Taussig (1947) says that cyanosis appears most often " about the age of 15 " and that after this the patients may live for ten years but not often for much more. If we may change her 15 years to between 5 and 25 or perhaps 30 , we agree with this terse summary.

Sex Incidence. In our series girls and women were rather more frequent than boys and men, the proportions being $3: 2$, but if the 100 cases where the diagnosis was made on clinical grounds alone (see Table III) are included, the sex incidence was equal, as it was in the series of Selzer (1949) and of Wood (1956). This equal incidence in the groups as a whole conceals some points of interest, to which we have found no references.

(1) More of our patients with a normal pulmonary arterial pressure were girls or womenamong the proved cases all except one man aged 23.

(2) There were far more women than men over twenty. Among the proved cases a third of the women (17 of 46) and less than a tenth of the men ( 2 of 29) were over this age; or, if the clinical cases are included, one-quarter of the women and less than a tenth of the men.

(3) The female patients who had become cyanotic were older than the male patients: 14 out of 16 of the former were over fifteen and 9 out of 11 of the latter were under this age. This was equally true if the clinical cases were included. 
Unless our series is atypical, the rise of pressure must occur sooner or be less well supported by boys than by girls, fewer of the boys surviving to adult life. The question is of practical importance for it would clearly follow that if life is to be saved, operation is indicated earlier and more urgently in boys than in girls (see later). More evidence is needed, for though we have seen few boys with a normal pressure, the rise of pressure with age in Groups 3-5 seems to be similar in the two sexes (see Fig. 7).

Elsewhere we have not found many data to support these differences and in the series of Wood (1957) there were rather more men than women over 20. However, in the cyanotic cases reported by Selzer and Laquer (1951), the male patients were equally divided into those under fifteen and those over twenty: while there were only 2 girls under fifteen but 9 women over twenty: the difference in the average ages at death was 9 years (22 against 31$)$. If the three series are combined there are 29 cyanotic boys (up to twenty) and 18 cyanotic girls, but over twenty there are 20 cyanotic men and 32 cyanotic women. The ratio of male to female patients was 1.7 to 1.0 under twenty and 0.6 to 1.0 over twenty. It seems unlikely that this difference could arise by chance when considering 99 cyanotic patients and it was almost the same if our 11 clinical cases were omitted.

\section{Clinical Picture}

Diagnosis. The systolic murmur and thrill are harsher and more striking than with atrial septal defects (A.S.D.) and are generally maximal lower, in the fourth left space: the pulmonary second sound is much less widely split. If, however, these signs are present without pleonæmic lungs on radioscopy, their significance must remain uncertain. We agree with Wood et al. (1954) that other lesions are proved to be present more often than a ventricular septal defect in cases where this was suspected on clinical grounds alone. We have many more patients of this type among our cases diagnosed clinically, sometimes wrongly, as for example one who has just been shown to have a trivial infundibular stenosis, than among those who have been proved, but few patients without symptoms have been catheterized.

The electrocardiogram does not help much in diagnosis. There may be an $\mathrm{rSR}^{\prime}$ complex but much less often than with A.S.D. Either the left or the right ventricle or both may show hypertrophy, and as Mannheimer et al. (1957) have pointed out, combined ventricular hypertrophy is the most common finding in cases corresponding to our groups 3, 4, and 5. Extreme right ventricular preponderance and strain are less common than they are in cases of A.S.D. with the same degree of pulmonary hypertension.

Where the site of the septal defect has been in doubt radioscopic evidence of left ventricular enlargement has, however, generally proved a correct indication that the defect is ventricular, but if the right ventricle is very large the left ventricle may appear wrongly to be a little large because it has been pushed over.

The Size of the Heart. This varies greatly-from normal to very large. We have divided the patients into four groups in Table IV - those who have a normal pulmonary arterial pressure, those who have pulmonary hypertension but are acyanotic, those who are cyanotic, and those who have aortic regurgitation.

The cases with a normal pulmonary pressure were almost equally divided into those with normal, slightly enlarged, large, and very large hearts (see Table IV). The normal-sized hearts were, as might be expected, in those with the smaller shunts (Fig. 3A). Among the acyanotic cases with a raised pulmonary pressure and a large or moderate shunt, the hearts were with one exception enlarged (Fig. 2) and more than half were very large (c.t.r. $60 \%$ or more)-as large as in cases of A.S.D. with shunts of the same size. By contrast, among the cyanotic cases, both children and adults, a large heart was much less common. It was of normal size in more than a quarter-a larger proportion than in any other group-and very large in less than a quarter (Fig. 3, B and C).

This high incidence of normal-sized hearts in cyanotic patients is difficult to understand. If at an earlier stage they have been acyanotic with a large left-to-right shunt they might be expected 
TABLE IV

The Size of the Heart in Ventricular Septal Defect

\begin{tabular}{|c|c|c|c|c|}
\hline \multirow[b]{2}{*}{ Groups } & \multicolumn{4}{|c|}{ Heart size } \\
\hline & $\begin{array}{l}\text { Normal } \\
\text { (c.t.r. } 50 \% \\
\text { or less) }\end{array}$ & $\begin{array}{l}\text { Slightly } \\
\text { enlarged } \\
(51-54 \%)\end{array}$ & $\begin{array}{c}\text { Large } \\
\text { (c.t.r. } \\
55-59 \%)\end{array}$ & $\begin{array}{c}\text { Very large } \\
\text { (c.t.r. } \\
60 \% \text { or more) }\end{array}$ \\
\hline 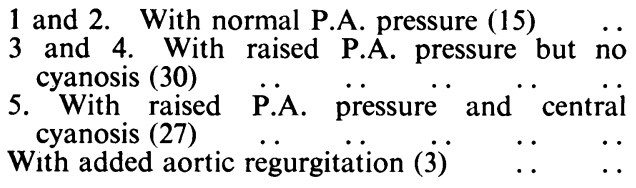 & $\begin{array}{l}4 \\
1 \\
8 \\
0\end{array}$ & $\begin{array}{l}4 \\
5 \\
1 \\
0\end{array}$ & $\begin{array}{r}5 \\
8 \\
12 \\
0\end{array}$ & $\begin{array}{r}2 \\
16 \\
6 \\
3\end{array}$ \\
\hline Total $\ldots$ & 13 & 10 & 25 & 27 \\
\hline
\end{tabular}

to have a large heart, but this does not seem to happen, though it does with similar cases with A.S.D.

Only two explanations are possible and we think each applies on occasion: that a large heart has become smaller, when the shunt and pulmonary flow have become smaller: or that the cyanotic patients have never had left-to-right shunts large enough to produce a large heart. In the latter case, even if they were not cyanotic from infancy, the pulmonary pressure may always have been high enough to prevent a large shunt, and then the right ventricle may be hypertrophied without much increase in the size of the heart. Similarly, the heart is often of normal size in cases of persistent ductus with a reversed shunt, in most of whom there is more evidence of pulmonary hypertension and consequent absence of a large left-to-right shunt even in infancy (Campbell, 1955).

On the other hand the fact that all the borderline cases where cyanosis was developing had large hearts (c.t.r. 57-67\%) and that two were observed becoming smaller (c.t.r. 60 to $55 \%$ and 59 to $55 \%$; Fig. 4) supports the former possibility. Until this has been observed more often and in adults, it is not easy to accept a large heart becoming of normal size when the patient is becoming worse, but we think this happens in some cases.

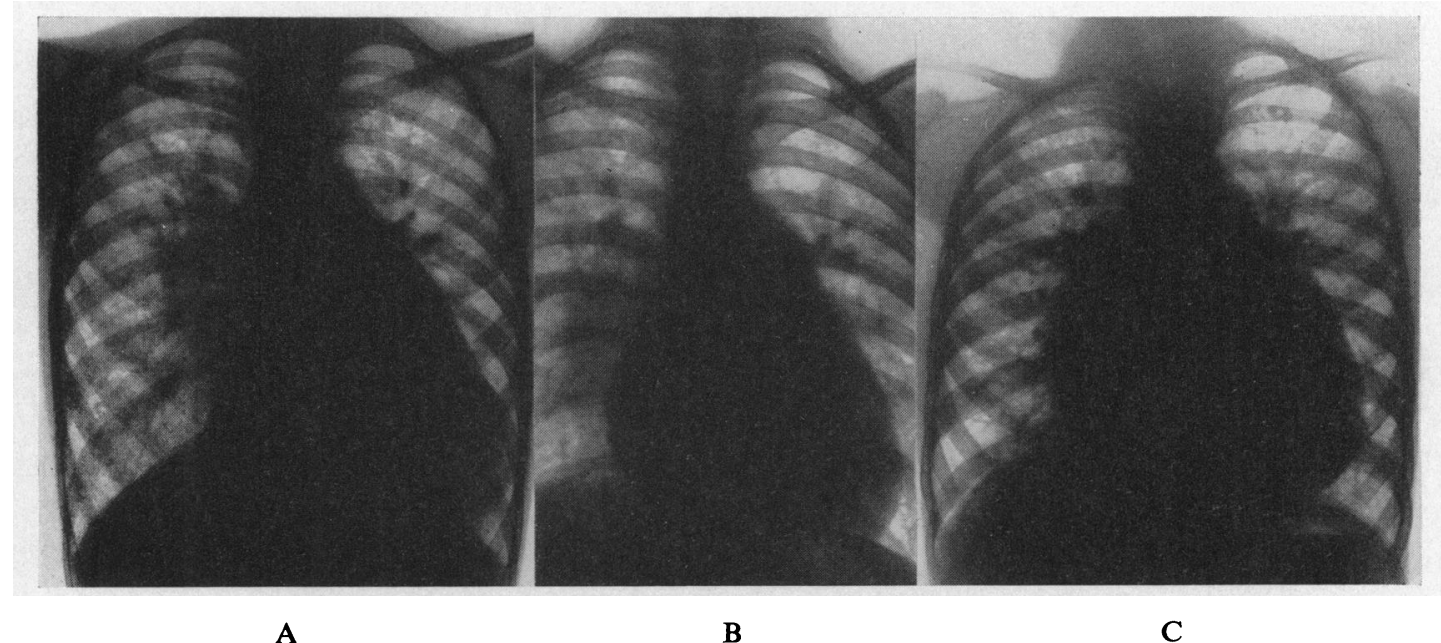

FIG. 2.-Large hearts from three acyanotic children with large left-to-right shunts. (A) From a boy of 11 with a c.t.r. of 65 per cent and a pulmonary arterial pressure (PAP) of 72/43 (Case 31). (B) From a boy of 11 with a c.t.r. of 56 per cent with a PAP of 90/60 (Case 39). From a girl aged 10 with a c.t.r. of 66 per cent and a mean PAP of $78 \mathrm{~mm}$., who died two years later (Case 0165). The rise in PAP was hyperkinetic in (A) and (B). 
In our cyanotic cases, a right-to-left shunt was generally associated with a low pulmonary flow, and never with a large one (see Table VI), and therefore with a normal right ventricular stroke volume. In consequence, reduction in the left-to-right shunt, even if accompanied by a rise in pulmonary pressure, might lead to the heart becoming smaller.

Pulmonary Regurgitation. This diagnosis was made in 19 of our 75 patients. Three others had aortic regurgitation (see later). In some there was a question of whether the regurgitation was aortic or pulmonary, because of the site of the murmur, the wide pulse pressure, or the appearance on radioscopy; but it was accepted as pulmonary because not more than one of these features was present in any case. Pulmonary regurgitation was less common in the younger patients-in onesixth of those in the first decade but in nearly one-third in later decades. In one boy who already had a large heart and pleonæmic lungs when he was two and was under regular observation, it was first observed when he was ten at a time when the pulmonary pressure was $72 / 43 \mathrm{~mm}$. (Case 31 ).

On the whole pulmonary regurgitation does not seem to add greatly to the patient's handicap and some in whom it has been present for seven years are still doing well. It was observed in only one patient where the pulmonary arterial pressure was normal but in over one-third (18 of 49) of those where it was raised. It is nearly three times as common as in A.S.D. where it was found in one in eight (Campbell et al., 1957). If, however, we allow for the smaller proportion of these patients who develop a raised pressure, its incidence in those with pulmonary hypertension is almost the same in those with atrial (7 of 18) and in those with ventricular septal defects (18 of 49)-rather more than one-third in each group.

Aortic Regurgitation. The association of this with ventricular septal defect has been recognized for some time (Laubry and Pezzi, 1921; Laubry et al., 1933; Routier et al., 1949). Generally the defect causes deformity of a cusp of the aortic valve and the regurgitation may be extreme.

We had no doubt of this diagnosis in three of our patients. One has an enormous heart (c.t.r. $69 \%$ ) but it has remained the same for nine years and he is able to lead a quiet life and go to school during the summer. The other two, however, have died (Cases 8 and 60, see p. 106). Clearly, it is a serious complication because both lesions are throwing a heavy strain on the left ventricle.

The Side of the Aortic Arch. The aortic arch was left-sided in all but two of our patients. These two, women aged 23 and 26, had been cyanotic from childhood (Cases 46 and 47). We do not think that they had any degree of transposition, but have seen other cases with a right-sided arch where the diagnosis of cyanotic V.S.D. was considered but replaced by that of partial transposition of the aorta and pulmonary trunk. Among the 100 patients diagnosed on clinical evidence only, two had a right-sided aortic arch: neither had shown any signs of becoming cyanotic when last seen, one aged 10 and the other aged 25 years. At least three patients had a left-sided superior vena cava (Cases 1, 7, and 27).

Changes of Rhythm were uncommon. Auricular fibrillation was found in one man, aged 30 years. Congenital heart block was found only in one cyanotic woman, aged 30; it has been rare in other series, confirming the view of Campbell and Thorne (1956) that the reputed association of heart block and ventricular septal defect is much less common than has been thought. There was, however, one boy aged 12, with pulmonary stenosis in addition (not, therefore, included in this series) who had at times complete and at times $2: 1$ heart block.

\section{Course ANd Prognosis}

Patients with small shunts and normal pulmonary pressures were generally free from symptoms. Most of those with larger shunts and a raised pressure were limited in what they could do but not as a rule seriously. Several of the older patients had carried on successfully with light work until they developed central cyanosis, but not for long after this. Even then, the downhill course was slower than we expected and often lasted for several years: some had recurrent hæmoptyses during this stage. It seems that these patients tolerate a high pulmonary pressure better than those where it is secondary to atrial septal defect. We think, however, that they are more disabled and have a worse outlook than most patients of comparable age with A.S.D. 
Patients who have Died. Nine of these patients are known to have died before they were twentyfive. It is true that three of them died after operation, that two had congestive failure from aortic regurgitation, and that two had additional lesions (pericarditis and ruberculosis); but they were ill patients before these terminal events and some already had congestive heart failure and others very large hearts so that we do not think they would have lived for long.

These patients represent the group who die young because they cannot support a shunt that is unusually large or because they fail to make the necessary adaptations. At least two of the older patients also have died.

One child died at the age of 3 (Case 16) and three others had severe symptoms that were getting worse though they actually died after operation (Cases 13, 18, and 26). All these four had enormous hearts which in three had been observed to increase in size (c.t.r. $71 \%, 61$ to $68 \%, 62$ to $75 \%$, and 65 to $73 \%$ ); all had a pulmonary pressure of about 75/50, not greatly below the systemic pressure.

Two boys, both aged 9, were fairly well until the onset of congestive failure a few months before their deaths (reported by Baylis et al., 1955): one with added aortic regurgitation had an enormous heart (c.t.r. 59 to $76 \%$ ) and remained acyanotic (Case 60 ), and the second became slightly cyanotic only during his last weeks (Case 27).

A girl, aged 15, also had a very large heart with free aortic regurgitation; she had no congestive failure while under observation but was becoming worse and died three years later: this was said to be from nephritis but we have not been able to get any details (Case 8). A girl, aged 10, had congestive heart failure when last seen two years before her death: at necropsy there was pericarditis, possibly rheumatic, but again we have no details except that it confirmed the diagnosis of V.S.D. The ninth, a boy aged 17, was cyanotic and moderately disabled: six years later he died with broncho-pneumonic tuberculosis and there was a large V.S.D. at the usual site (Case 42).

The tenth, aged 34, had been more disabled for two years and cyanotic since childhood; and the pulmonary pressure was $155 / 95$, about the same level as the systemic: she died four years later with pulmonary congestion and hæmoptyses (Case 54). The eleventh, aged 47, did domestic work till four years before: she was only a little cyanotic but died two years later (Case 57).

\section{HÆMOdYNAMIC ASPECTS}

In this section we are including 57 (Tables V and VI) of the 75 patients discussed so far: 38 were catheterized at Guy's Hospital and 19 at other centres, mainly the National Heart Hospital. We are omitting (a) six who have been catheterized since the tables and diagrams for this section were completed, (b) four where the data of catheterization were incomplete, and (c) eight where a

TABLE V

Hemodynamic Data in Patients with a Normal Pulmonary Arterial Pressure

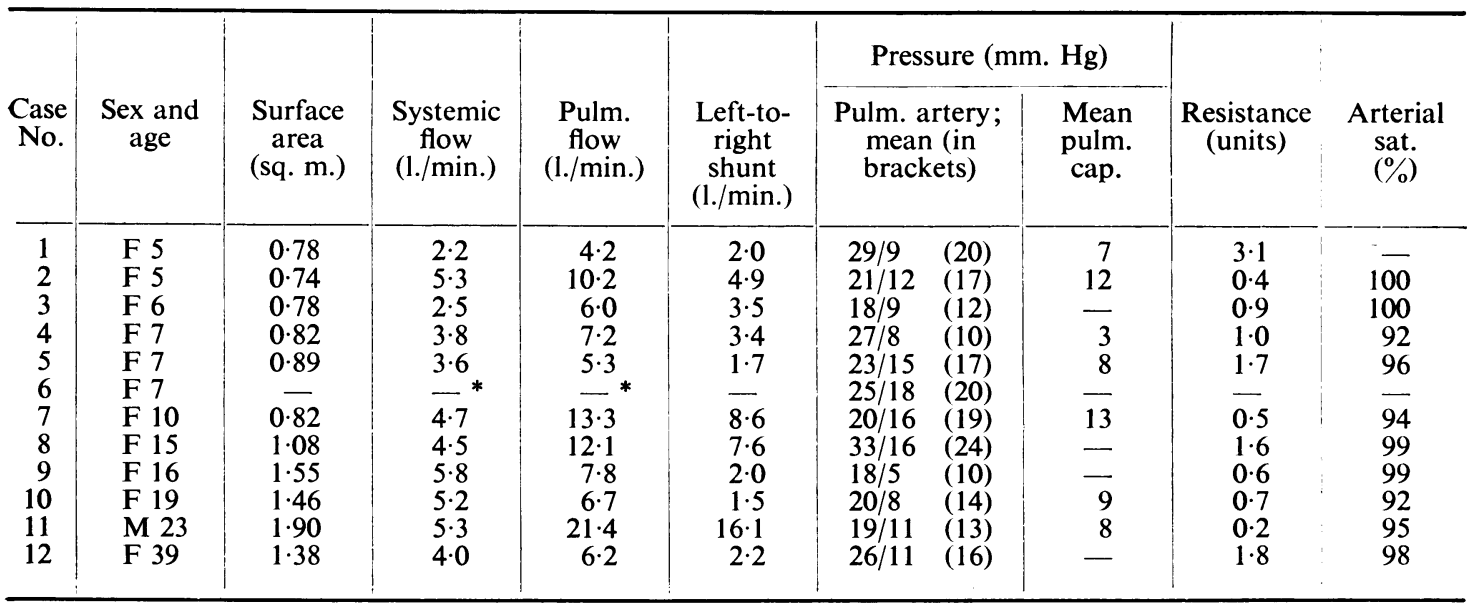

* Not calculable owing to error in estimating arterial oxygen content. 
TABLE VI

Hemodynamic Data in Patients with a Raised Pulmonary Arterial Pressure

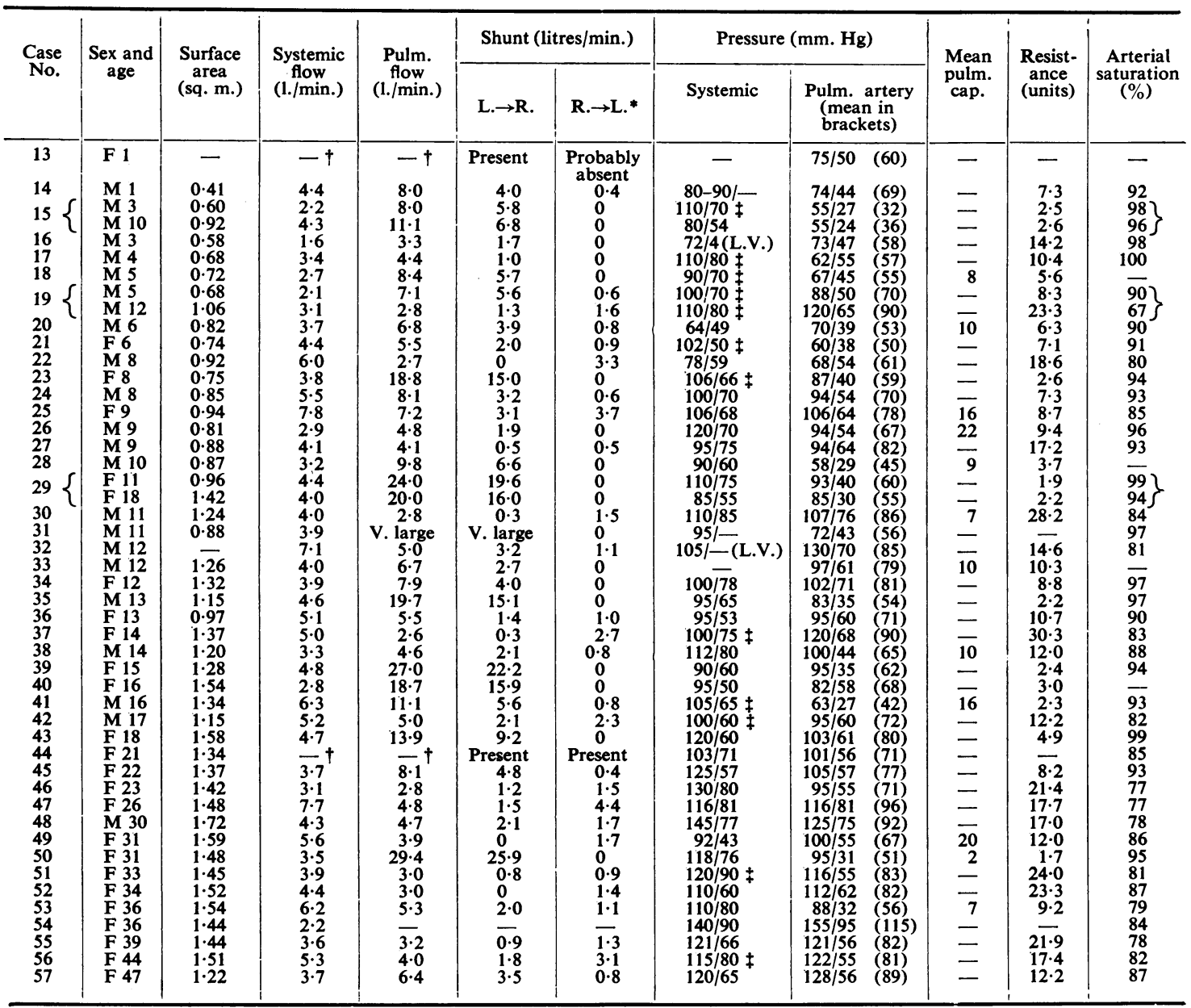

* The overall shunt is obtained by subtracting the lesser of these from the greater.

† Oxygen consumption not measured.

$¥$ Not measured during cardiac catheterization.

small pressure gradient across the pulmonary valve prevented us using them for study of the relationship of the pulmonary artery pressure to age and other factors, even though we thought there was no organic stenosis. These last will be discussed with another 15 patients who had a left-toright shunt through a ventricular septal defect and also a gradient that we thought significant of pulmonary stenosis (Brotmacher and Campbell, 1958).

Methods. General anæsthesia was employed in 13 subjects and barbiturate sedation in the remainder. Every attempt to secure basal conditions was made, and the oxygen consumption was within 25 per cent of normal for the age and sex in over 70 per cent of those where there were adequate data.

Pressures were measured from the mid-thoracic plane using Sanborn, Southern Instruments, or Hamilton manometers. Oxygen uptake was measured with a Benedict spirometer and the percentage saturation of the blood samples estimated by the Haldane method. In those patients with pulmonary hypertension in whom the catheter could not be wedged successfully, the pulmonary arteriolar resistances were calculated by using the mean of the measured pulmonary capillary pressures, which was $11 \mathrm{~mm}$. $\mathrm{Hg}$. 
The oxygen content of the right ventricular blood was at least $1 \mathrm{ml}$. per $100 \mathrm{ml}$. higher than the right atrial in all the acyanotic patients, except one who developed ventricular tachycardia when the catheter was in the right ventricle. It was higher by this amount in 10 of the 18 cyanotic patients: in two of the other 8 the aorta was entered, in two simultaneous filling of the aorta and pulmonary artery was shown by angiocardiography and in four the diagnosis was based on clinical grounds and on a right ventricular pressure that approximated to the systemic.

The oxygen content of the pulmonary arterial blood exceeded the right ventricular sample by more than $0.5 \mathrm{ml}$. per $100 \mathrm{ml}$. in 12 patients, but this was attributed to a streaming effect rather than to a second shunt. In one of these a persistent ductus was excluded at autopsy, and in a second such case by aortography. This difference in oxygenation was observed by Bowers et al. (1955) also, in a patient where a communication between the aorta and pulmonary artery was excluded at operation.

\section{Pulmonary Flows and ShunTs}

The pulmonary blood flows in the 51 patients where the data were available ranged from below normal (in patients with veno-arterial shunts) to values that were too large to be measured with any accuracy (Tables V and VI and Fig. 5). Among patients with a normal pulmonary arterial pressure

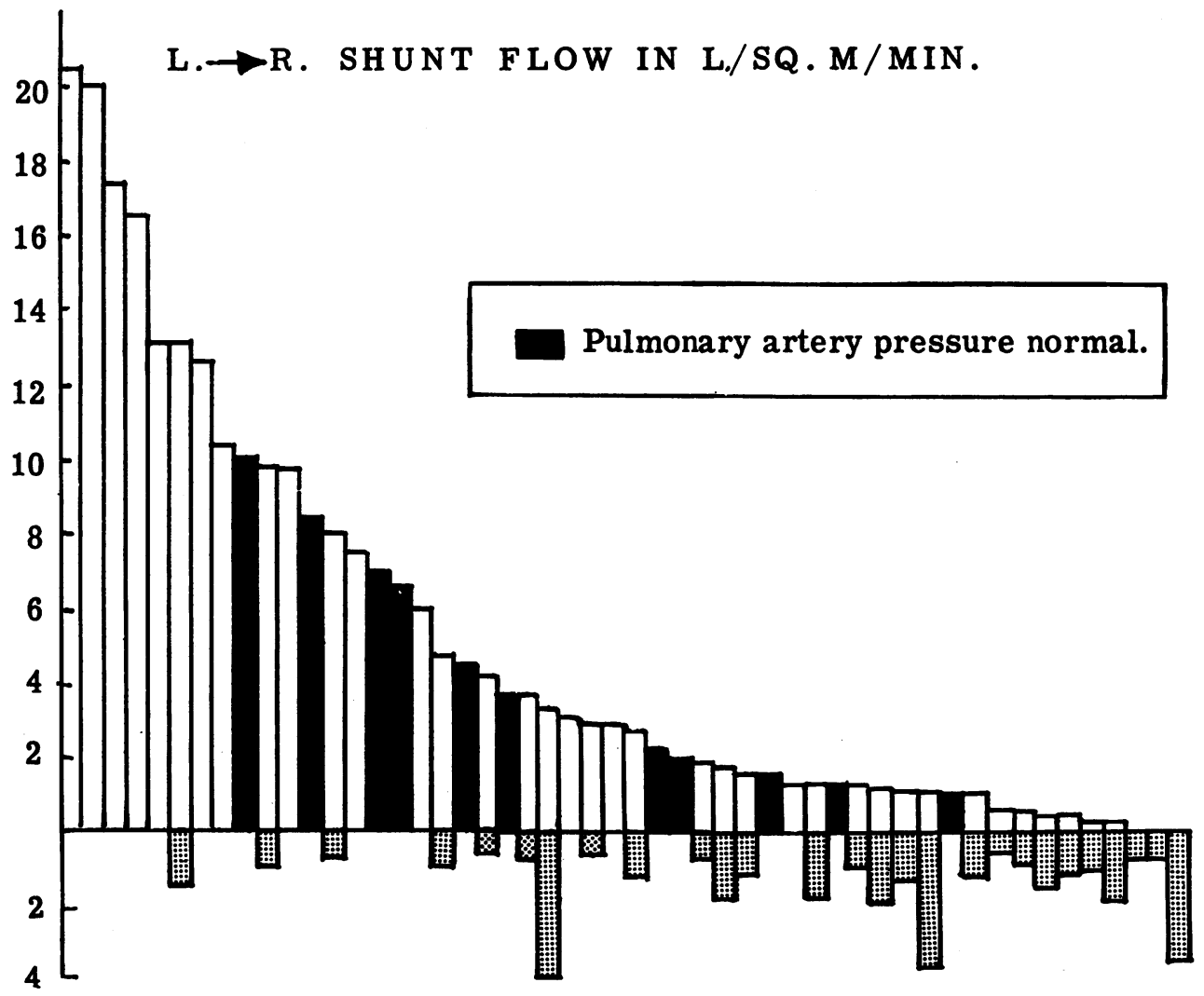

R. $\rightarrow$ L. SHUNT FLOW IN L./SQ. M. /MIN.

FIG. 5.-The size of the shunts in litres/sq. $\mathrm{m} . / \mathrm{min}$. in ventricular septal defect. Above the line, the left-to-right shunts arranged in order of size; the dark shading shows the patients with normal pulmonary arterial pressures. Below the line; lightly shaded, the right-to-left shunts. 
there were (1) 7 with shunts that averaged 2.4 litres a minute and (2) 4 with shunts that averaged $8 \cdot 1$ litres a minute, a shunt comparable with that in many cases of atrial septal defect.

(3) In 8 patients the rise of pulmonary pressure was hyperkinetic, the pulmonary resistance being under 3 units, and the average shunt was 15.6 litres a minute, which is comparable with the larger shunt of many cases of A.S.D.

(4) In 17 patients the pulmonary resistance was raised (generally between 6 and 12 units) and the left-to-right shunt was much smaller, but still averaged 3.5 litres a minute. There was sometimes also a right-to-left shunt that was still too small to make the patient frankly cyanotic.

(5) Finally, 15 cyanotic patients with a very high pulmonary resistance (nearly always over 12 units) had a right-to-left shunt large enough to lower the arterial $\mathrm{O}_{2}$ saturation to 87 per cent or less. Even so, most of them had still a left-to-right shunt, but it averaged only 1.3 litres and could not be measured in three.

These groups overlap but give a general picture of the position. The proportion in each group is quite unlike what is found with atrial septal defect, where nearly all children and half the adults are in the first three groups and many fewer in the fourth and fifth (Campbell et al., 1957).

The patients with the larger veno-arterial shunts were as a group older than the others, and with their inclusion the pulmonary flows and shunts were somewhat lower in adult life than in childhood and adolescence. Otherwise there was no relationship between age and pulmonary flow, whether the pulmonary pressure was normal or was raised. Even when patients with normal and with raised pulmonary resistance were considered separately, no age trends were discernible in the acyanotic group.

\section{Arterial ANOXfemia}

There were 19 patients with clinical cyanosis, associated with polycythæmia, clubbing of the fingers, or both. Significant arterial desaturation (to under $90 \%$ ) was seen only in conjunction with a high pulmonary arterial pressure (Fig. 6) and was therefore more common in older patients. It was seen in 2 of 21 patients in the first decade, in 5 of 20 in the second decade, and in 12 of 16 in the third decade and after-in one-fifth of those under 20 but in three-quarters of those over this.

Taussig (1947), in describing Eisenmenger's complex as a distinct entity, suggested a pulmonary factor as part cause for the arterial desaturation. However, a sample from the left atrium was between 94 and 100 per cent saturated in three patients (Cases 22, 32, and 55) in whom it was possible to manipulate the catheter into this chamber, the absence of shunting in either direction at atrial level suggesting that an unsealed foramen ovale had been intubated. Similar findings have been described by Soulié et al. (1953) and Kjellberg et al. (1955). In the 12 patients with pulmonary hypertension in whom pulmonary capillary pressure was measured, it was well below the levels at which extravasation of fluid is likely to interfere with oxygen uptake. We consider that the arterial oxygen desaturation can be accounted for entirely by the right-to-left shunt.

\section{Pulmonary Arterial Pressure}

The pulmonary pressure was normal in 12 (Table V) and raised in 45 of our patients (Table VI). The two groups are quite distinct (Fig. 7): in one there is no rise of pressure, in the other it is considerable, and there is no intermediate group with a slight or moderate rise of pressure. This clear-cut distinction appears to characterize the series of Wood (1950) and of Kjellberg et al. (1955) but not the series of Mannheimer et al. (1957) or Blount et al. (1955). Blount's patients are not strictly comparable, as they were observed at the high altitude of Denver; and perhaps for this reason did not include any with a normal pulmonary pressure.

Wood et al. (1954) have suggested that there is a critical size of defect, about $1.0 \mathrm{~cm}$. in diameter, below which the pulmonary pressure is unlikely to rise much, and above which it is likely to approximate to that in the left ventricle. This concept is supported by the observations of Griffin and 


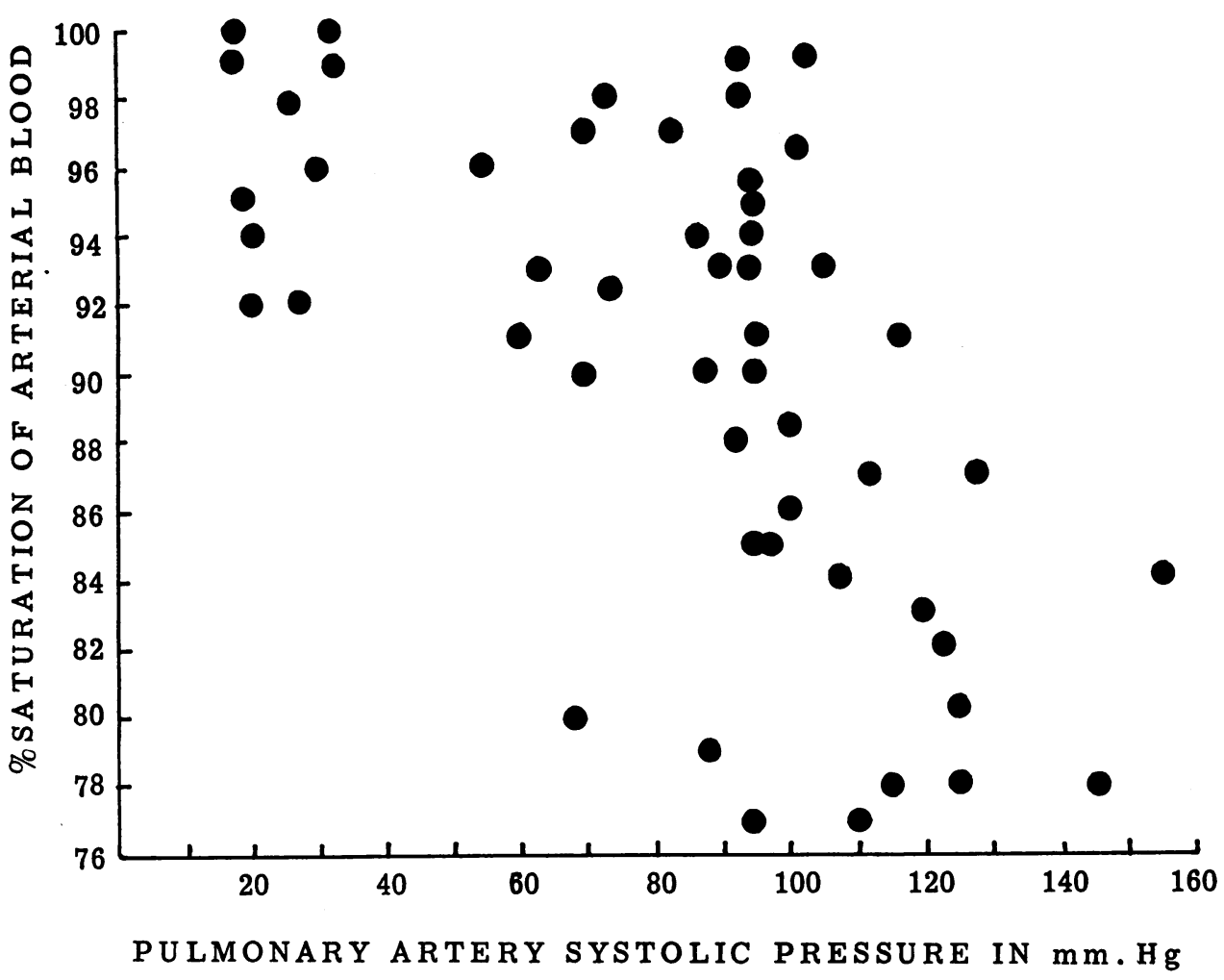

FIG. 6.-The relationship of the arterial oxygen saturation to the pulmonary arterial systolic pressure. Up to a systolic pressure of $85 \mathrm{~mm}$. $\mathrm{Hg}$ most patients show normal arterial oxygen saturation and only one is under 90 per cent. Above $110 \mathrm{~mm}$. $\mathrm{Hg}$ most show considerable desaturation and only one is over 90 per cent. At pressures between 85 and $110 \mathrm{~mm}$. the findings are variable, this depending partly, no doubt, on the level of the systemic pressure in the patient concerned.

Essex (1951) who found that most dogs in which they produced a ventricular septal defect of $0.8 \mathrm{~cm}$. survived while those in which it was $1.2 \mathrm{~cm}$. invariably died. Probably patients with pulmonary hypertension are those whose defects are larger than this critical size and patients with normal pulmonary pressures those whose defects are smaller than this.

Only 7 of the 12 subjects with normal pulmonary pressures had shunts small enough to be included in our Group 1 : in 4 (Group 2) the shunts were of moderate size, but the pressures remained normal because the pulmonary resistance was low. The systemic flows were about normal, from which it follows that, provided the shunt is not very large, a high resistance to pulmonary flow is not always essential for the maintenance of an adequate systemic flow. In 7 patients in these two groups the pulmonary capillary pressure was measured and found to be normal, so that pulmonary hypertension does not seem to play any vital part in preventing pulmonary odema in ventricular septal defects, as has been postulated in mitral stenosis (Wood, 1954).

No tendency for the pressure to rise with age could be seen among the patients with a normal pressure: they were mostly under 20 , but two were 23 and 39 years of age. Within the group with a raised pressure the systolic pressure tended to rise with age (Fig. 7A), the correlation being highly significant $(r=0.69, t=6.23, P<0.001)$. The mean increase was $1.3 \mathrm{~mm}$. each year and it was rather more in the acyanotic than in the cyanotic cases. The rise in diastolic pressure was smaller and of doubtful significance $(r=0.27, t=1.84,0.1>P>0.05)$ : it averaged $0.5 \mathrm{~mm}$. each year (Fig. 7B). We shall discuss the relationship of this rise to the normal rise of systemic pressure with age (see p. 113). 


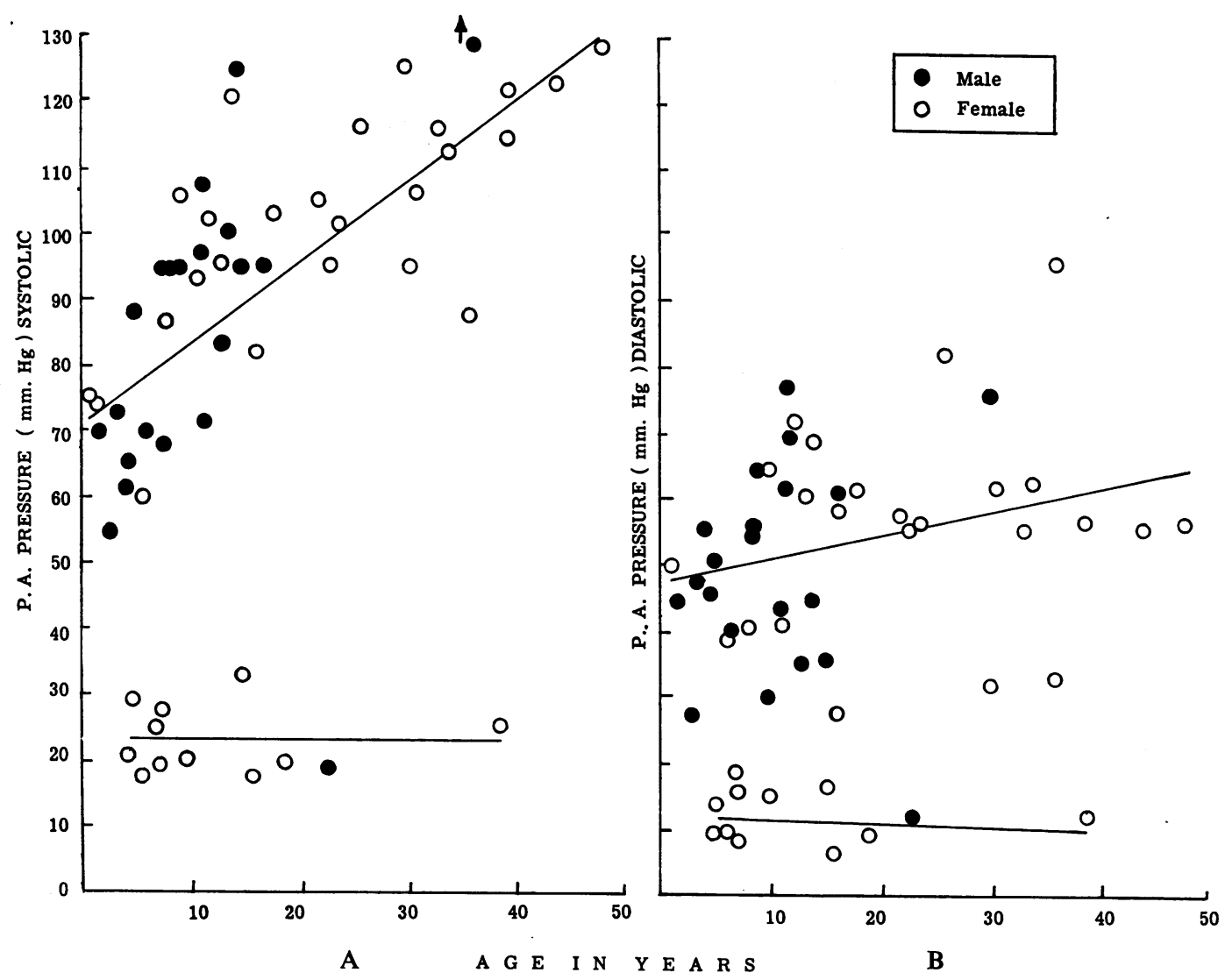

Fig. 7.-The relationship of pulmonary arterial pressure to age. (A) On the left, the systolic pressures are separated into two groups-those with a normal pressure where there is no tendency to rise, and those with a raised pressure where it rises progressively. (B) The diastolic pressure is shown on the right: it shows these two features, but much less than the systolic pressure does. The calculated regression lines are shown by continuous lines.

The fact that the systolic pressure rises more than the diastolic results in a rise in pulse pressure with age and a progressive increase in the ratio of the pulse pressure to the diastolic pressure. This was not due to the inclusion of patients with pulmonary regurgitation, for these did not have higher pulse pressures or lower diastolic pressures than those of corresponding age in whom the pulmonary valve was competent. This rise in pulse pressure suggests that decreasing distensibility of the pulmonary vascular bed plays some part. The smaller rise in diastolic pressure means that the pulmonary hypertension of an adult with a ventricular septal defect is more like the systemic pressure of 200/90 seen in an atherosclerotic patient than the pressure of 200/120 seen in one with essential hypertension.

No hæmodynamic basis for the difference in the age incidence of the two sexes (see p. 101) has been found; the pulmonary arterial pressures did not differ, when allowance was made for age (Fig. 7), and the mean pulmonary flow per square metre in the boys under 20 was actually a little less than that in the girls.

The rate of rise of pressure is greater in the acyanotic than in the cyanotic cases. Arterial anoxæmia and the changes in blood viscosity associated with polycythæmia are, therefore, not likely to be important. The mean systolic pressures of the cyanotic and the acyanotic groups were $112 \mathrm{~mm}$. and $85 \mathrm{~mm}$. respectively, but this difference can be largely accounted for by the mean age of the cyanotic patients being 24 and that of the acyanotic ones only 12 years. This, however, 
does not explain the correlation between age and pulmonary pressure for it was found to retain its significance $(r=0.65, t=4.34, P<0.001)$ when the cyanotic patients were excluded from the analysis.

The higher pulmonary arterial pressure of the older patients suggests that it has increased with age, and so does the clinical observation of the frequent development of cyanosis during the second and third decades. Campbell and Baylis (1956) found that in patients with coarctation of the aorta, the trends deduced from single measurements of the blood pressure and from serial observations tallied well. It would seem reasonable to conclude from the present findings that when the pressure is already raised in early life, it rises further with age. This has practical implications, for in a patient of, say, two years of age a pulmonary pressure of 60/30 cannot be dismissed as only moderately raised, for it is likely to rise further, probably to the stage where the shunt will become reversed.

In patients with an atrial septal defect or the common type of persistent ductus, the pulmonary pressure usually falls soon after birth and, if it rises again, this happens much later, often in the third, fourth, or fifth decades. Our findings suggest that this does not happen in patients with a ventricular septal defect and that the pulmonary pressure is high, in part at least, from birth or from a very early age.

\section{Ventricular Pressure Differentials}

(a) During Diastole. In 8 of 14 patients in whom adequate records were obtained, the lowest pulmonary capillary pressure in each patient exceeded the corresponding right ventricular diastolic pressure. The left atrial and left ventricular diastolic pressure also must, therefore, have been greater than the right ventricular. Shunting of blood through the defect is usually thought to take place during systole, accounting for the pan-systolic murmur. In the presence of these diastolic pressure differences a left-to-right shunt must be present in diastole, despite the absence of a murmur, as it seems unlikely that the defect can be closed in this phase of the cardiac cycle.

(b) During Systole. The ventricular septal defect brings the lesser circulation into direct contact with the ventricle in which the pressure normally tends to rise with the years. The fact that the right ventricular pressure may remain normal shows that the pressure differential may remain normal in spite of the defect, but this can happen only if it is small. Several authors have spoken of equalized pressures in the two ventricles and we wish to examine the evidence for this. It is unusual for the catheter to pass through the defect to the left ventricle but a measure of systemic pressure was obtained during catheterization in 32 patients with pulmonary hypertension (Table VI). The pressure in the left ventricle was recorded twice and in the aorta three times. The pressure in the brachial (or femoral) artery was recorded directly in 10 patients and was measured by sphygmomanometry in the remaining 17 . The conclusions that can be drawn from observations as heterogeneous as these are somewhat limited, especially as the time elapsing between the measurement of pulmonary and systemic pressures varied greatly. The frequency with which the pulmonary pressure appeared to exceed the systemic shows the effect of differences in timing and techniques, for it is unlikely that this was really the case.

Nevertheless, comparison of pulmonary and systemic pressures does reveal one noteworthy feature. The difference was never greater than $32 \mathrm{~mm}$.: in over three-quarters of the acyanotic patients the pulmonary systolic pressure was within $20 \mathrm{~mm}$. of the systemic and in almost half it was within $10 \mathrm{~mm}$. As in some cases it appeared to exceed the systemic pressure by as much as $20 \mathrm{~mm}$. we cannot accept all the differences in the other direction as significant. In most large defects, therefore, the pressure differential is small and the shunt can be reversed by a slight rise in pulmonary arterial pressure.

The Rise of Normal Systemic Pressure with Age. It is not easy to find an accepted standard for the rise of blood pressure from infancy to old age, especially as many series deal with school children only and others with adults only. For children we have used average figures from various sources and for adults those of Hamilton et al. (1954). 
The systolic blood pressure rises in an almost linear relationship with age up to about 15 years, $2.3 \mathrm{~mm}$. a year, and thereafter less steeply, about $0.7 \mathrm{~mm}$. a year. The diastolic rise is similar but smaller, $1.2 \mathrm{~mm}$. a year below 15 and $0.4 \mathrm{~mm}$. after. These figures show that the normal rise in the systemic circuit and the rise in the pulmonary circuit in our patients are of the same order. However, the right ventricular systolic pressure must rise more than the left in those patients who become cyanotic. In our cases it rose $1.3 \mathrm{~mm}$. a year and this is more than the rise in systemic pressure after 15 and may explain the liability to develop cyanosis after this age.

\section{Pulmonary Arteriolar Resistance}

There is no tendency for the normal adult pulmonary arterial pressure to increase with age and Kjellberg et al. (1955) have shown that in 13 normal children its level was about the same as in adults. Brotmacher and Deuchar (1956) have adduced evidence that the cardiac index is about the same in children and adults. It would seem likely, therefore, that the pulmonary resistance index (which we have used so that children and adults could be compared) does not change significantly as a normal subject grows older.

We have found in our cases that the resistance index tends to increase with age (Fig. 8). It was normal in over one-third of those with pulmonary hypertension under 20 but in only one of those over 20 years. The cyanotic patients had higher resistances than the acyanotic, but there was some overlapping.

The left-to-right shunt and the pulmonary blood flow per unit of surface area were measurable in 51 patients, who in Table VII have been divided into the groups we have suggested except that

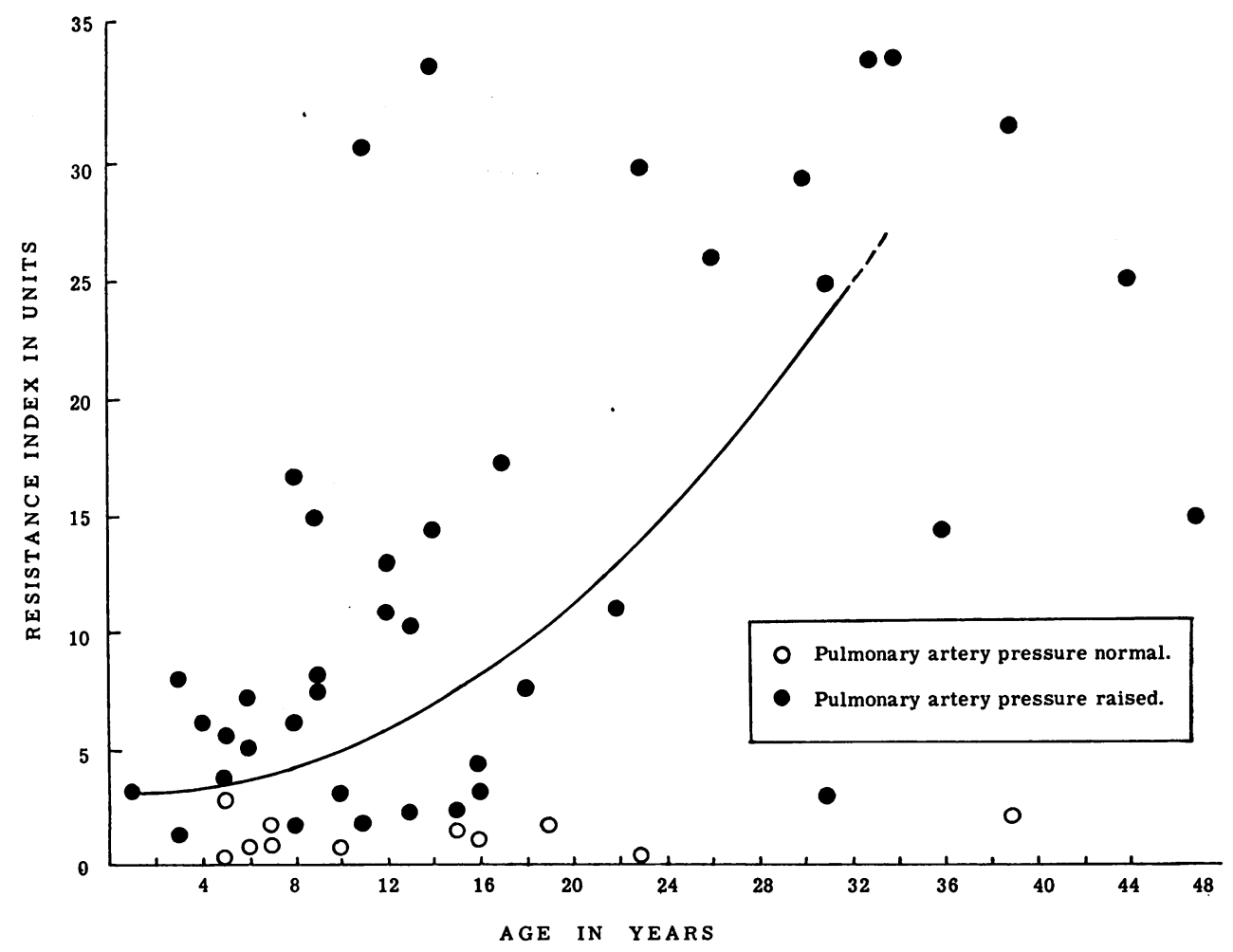

Fig. 8.-The relationship of the pulmonary arteriolar resistance to age. The mean resistance index rises with age slowly at first and more steeply during and after the second decade. Exceptionally, it may remain normal in patients over twenty or may be somewhat raised in young children before they are five. The estimated relationship is shown approximately by the curved line. 
TABLE VII

Relationship of Pulmonary Arteriolar Resistance to Shunts and Cyanosis

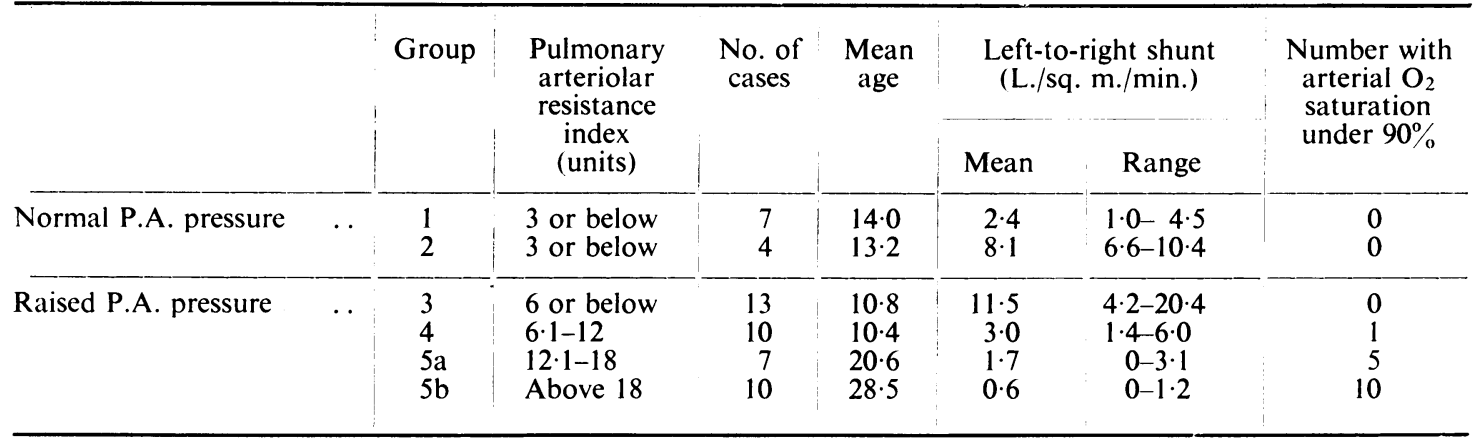

in this instance the decision has rested only on the pulmonary arteriolar resistance. Pulmonary hypertension, even in the hyperkinetic group, is not determined solely by the size of the left-to-right shunt, for those in Group 3 did not always have larger left-to-right shunts than those with normal pulmonary pressures.

Increase in the pulmonary resistance is associated with progressive diminution in the size of the left-to-right shunt and the development and progressive increase of the right-to-left shunt (Table VII). The groups overlap to some extent: for example, some patients in Group 4 had a larger left-to-right shunt and less arterial desaturation than others in Group 5a. This overlapping emphasizes the absence of any clear cut division between cyanotic and acyanotic cases of ventricular septal defect.

In patients with pulmonary hypertension, the tendency of pulmonary resistance to rise with the years is shown again by the greater average age of the high resistance cases (Group 5). In contrast, the patients with normal pressures are, as a group, older than those with hyperkinetic pulmonary hypertension (Group 3) or with a moderate rise of pulmonary resistance (Group 4). The pulmonary pressure is therefore not very likely to become high as a late complication in patients where it is normal.

Wood et al. (1954) state that " high pulmonary vascular resistance does not develop over the years but is determined shortly after birth." In our view, the pulmonary pressure is usually high from birth: at first the rise is mainly hyperkinetic, but as the years pass the pulmonary arteriolar resistance gradually rises, reducing the left-to-right shunt and causing a right-to-left shunt. Blount et al. (1955) also concluded that the pulmonary arteriolar resistance increases with age.

\section{Changes Observed in the Individual Patient over the Years}

Since most of this was written, three patients have been recatheterized after an interval of about seven years. The first showed all the changes that we have deduced from the general study, but the second and third still showed very little change.

When he was 5 , a boy had a pulmonary flow of $7 \cdot 1$ litres a minute with a left-to-right shunt 5.6 and a right-to-left shunt of $0 \cdot 6$ litres. Seven years later he was more cyanotic but not much more disabled: his pulmonary flow was now less than the systemic, the left-to-right shunt was greatly reduced, and the right-toleft shunt was large enough to have reduced the arterial $\mathrm{O}_{2}$ saturation from 90 to 67 per cent. When 5 , his P.A.P. was $88 / 50$ against a clinical systemic pressure of $100 / 70$, and when he was 12 it was 120/65 against a systemic pressure 110/80. The pulmonary pressure had risen moderately but the resistance had risen greatly, from 8 to 23 units (Case 19, Table VI).

The second had a large left-to-right shunt when he was $3 \frac{1}{2}$ with a raised pulmonary pressure, 55/27. When 10 , he was still acyanotic but the pulmonary flow was relatively smaller, 2.6 times instead of $3 \cdot 7$ times the systemic flow: there was hardly any change in the pulmonary pressure or in the pulmonary arteriolar resistance (Case 15). 
The third had an enormous pulmonary flow of about 24 litres a minute when she was 11, with a P.A. pressure of $98 / 40$, a rise that was entirely hyperkinetic. Seven years later there was little change. The systemic systolic pressure had been $17 \mathrm{~mm}$. higher than the pulmonary but now the difference was hardly significant: the resistance index had risen from 1.8 to 3.2 units. On both occasions she was acyanotic and remained so on exertion (arterial oxygen 99 and $94 \%$ ) (Case 29).

\section{INCREASE IN SIZE OF DEFECTS}

We do not know whether ventricular septal defects increase in size pari passu with the patient's growth, but there was some evidence for this from the necropsy series of Selzer (1949). In general, they are very similar anatomically to the defects in Fallot's tetralogy and the conclusions of Brinton and Campbell (1953) and subsequent experience suggests that these latter defects increase in size. For example, in 16 cases, aged between 4 and 12, the mean diameter of the defect was $1 \cdot 1 \mathrm{~cm}$. and in 8 cases between 17 and 36, it was $1.8 \mathrm{~cm}$. Presumably the death rate is heavier among those with a larger defect, so that if in the survivors it did not become larger with growth one would expect the older patients to have smaller defects. Whether the defect enlarges in the same proportion as the heart generally. is less certain. Some children seem to adjust to their defect better as time goes on and this might be because it has grown less than the rest of the heart. For example, one boy, aged 10, seemed unlikely to survive his first three winters and was frequently in hospital with pulmonary congestion, but has been much better since (Case 15). He has recently been catheterized a second time and the shunt, relatively to his size, is less than it was seven years before.

\section{SUMMARY AND CONCLUSIONS}

This paper is based on 75 patients in whom the diagnosis of ventricular septal defect was accepted after cardiac catheterization, regardless of whether the patient was cyanotic or acyanotic. Another 100 in whom the diagnosis rested on clinical grounds alone have been used in considering the age and sex incidences.

Nearly three-quarters of all the patients were under 20 years of age, but the cyanotic patients were more equally distributed through the first four decades, showing that patients become cyanotic throughout this period.

Although the sex incidence is equal, there were far more women than men over 20 , and among the cyanotic the female were older than the male patients. The prognosis in boys and men, therefore, appears to be more serious than in girls and women.

Some of the clinical features are reviewed shortly. We think the terms maladie de Roger and Eisenmenger's complex have outlived their usefulness and should no longer be used, and still less the term Eisenmenger's syndrome which adds confusion instead of clarity. Classification should depend on the size and direction of the shunt and the level of the pulmonary arterial resistance.

In acyanotic patients the heart will be large if the shunt is large. In cyanotic patients, it may be large or may be normal in size when the left-to-right shunt has never been large or has ceased to be so because of the high pulmonary arterial pressure. Pulmonary regurgitation is found in one-third of the patients with pulmonary hypertension.

If the patient survives infancy, the prognosis is fairly good for fifteen years or so; but unless the defect and the shunt are small, it becomes increasingly bad thereafter, and few such patients survive to 40 years of age.

In ventricular, as opposed to atrial septal defects, the pressure may be transmitted directly from the left to the right ventricle. The pressure differential between the ventricles will be normal if the defect is small, in which case the shunt is generally less than 3.5 litres a minute, though sometimes much larger - presumably with a defect of intermediate size. Generally, however, the defect is larger and the pressure differential is small, no more than 10 or $20 \mathrm{~mm}$.; this enables the heart to maintain a reasonable systemic flow in spite of the large shunt. 
The right ventricular and pulmonary arterial pressures are already high in small children, probably from birth. Although at first the rise is generally hyperkinetic, subsequently it is due partly to the natural rise in left ventricular pressure but mainly to the pulmonary arteriolar resistance, which increases with age and becomes the most important factor.

At some stage, often in the third decade but sometimes earlier and sometimes later, the right ventricular pressure may rise rather faster than the left so that the left-to-right shunt becomes much smaller, a right-to-left shunt develops, and the patient becomes cyanotic. These changes are adequately accounted for by the levels of the right and left ventricular pressures, and there is no need to invoke any pulmonary factor to explain the cyanosis or to place much importance on the anatomical position of the aorta. We are, therefore, in agreement with Selzer (1953) and Blount (1955) in treating the acyanotic and cyanotic cases as a single group. The exact stage at which these changes make successful operation for closing the ventricular septal defect impossible will need precise definition, but it may be relatively early.

\section{REFERENCES}

Baylis, J. H., Campbell, M., Gilmore, H. R., and Hudson, R. (1955). Guy's Hosp. Rep., $104,114$.

Becu, L. M., Fontana, R. S., Du Shane, J. W., Kirklin, J. W., Burchell, H. B., and Edwards, J. E. (1956). Circulation, 14, 349.

Blount, S. G., Jr., Mueller, H., and McCord, M. C. (1955). Amer. J. Med., 18, 871.

Bowers, D., Burchell, H. B., and Wood, E. H. (1955). Proc. Mayo Clin., 30, 261.

Brinton, W. D., and Campbell, M. (1953). Brit. Heart J., 15, 335.

Brotmacher, L., and Campbell, M. (1958). Brit. Heart J. To be published.

, and Deuchar, D. C. (1956). Clin. Sci., 15, 441.

Brown, J. W. (1955). Congenital Heart Disease. London. Staples Press.

Burchell, H. B., Taylor, B. E., Pollack, A. A., DuShane, J. W., and Wood, E. H. (1948). Proc. Mayo Clin., $23,507$.

Campbell, M. (1954). Brit. Heart J., 16, 275.

- (1955). Brit. Heart J., 17, 526.

- and Baylis, J. H. (1956). Brit. Heart J., 18, 475.

—, Neill, C., and Suzman, S. (1957). Brit. med. J., 1, 1375.

- and Thorne, M. G. (1956). Brit. Heart J., 18, 95.

Dexter, L., Haynes, F. W., Burwell, C. S., Eppinger, E. C., Sosman, M. C., and Evans, J. M. (1947). J. clin. Invest., 26, 561 .

Griffin, G. D. J., and Essex, H. E. (1951). Surg. Gynac. Obst., 92, 325.

Hamilton, N., Pickering, G. W., Roberts, J. A. F., and Sowry, G. S. C. (1954). Clin. Sci., $13,11$.

Handelsman, J. C., Bing, R. J., Campbell, J. A., and Griswold, H. E. (1948). Bull. Johns Hopk. Hosp., $82,615$.

Joly, F., Carlotti, J., and Scot, J. R. (1951). Arch. Mal. Cour., 7, 602.

Kjellberg, S. R., Mannheimer, E., Rudhe, U., and Jonsson, B. (1955). Diagnosis of Congenital Heart Disease. Chicago.

Laubry, C., and Pezzi, C. (1921). Traité des Maladies Congénitales du Caur. J. B. Baillière et fils, Paris.

Laubry, C., Routier, D., and Soulié, P. (1933). Rev. Méd. Paris, 50, 439.

Mannheimer, E., Ikkos, D., and Jonsson, B. (1957). Brit. Heart J., 19, 333.

Marquis, R. M. (1950). Brit. Heart J., 12, 265.

Roger, H. (1879). Bull. Acad. Méd., 8, 1074.

Routier, D., Soulié, P., and Bernal, P. (1949). Arch. Mal. Cæuur, 42, 765.

Selzer, A. (1949). Arch. intern. Med., 84, 798.

(1954). J. Amer. med. Ass., 154, 129.

_ and Laquer, G. L. (1951). Arch. intern. Med., 87, 218.

Soulié, P., Voci, G., Carlotti, J., and Joly, F. (1953). Arch. Mal. Cour, 46, 481.

Taussig, H. B. (1947). Congenital Malformations of the Heart. New York, Commonwealth Fund.

Wood, P. (1950). Brit. med. J., 2, 639 and 693.

(1954). Brit. med. J., 1, 1051 and 1113.

(1956). Diseases of the Heart and Circulation. 2nd ed. Eyre and Spottiswode, London.

(1957). Personal communication.

__, Magidson, O., and Wilson, P. A. O. (1954). Brit. Heart J., 16, 387. 